\title{
Empirical Study on the Structural and Spatial Difference between Indus- trial Pollutant Emissions and Economic Growth in Yangtze River Delta Region
}

\author{
Shen Fei* \\ School of International Business, Zhejiang Yuexiu University of Foreign Languages, Shaoxing City, Zhejiang Province, \\ 312000, China
}

\begin{abstract}
The provinces and cities located in the Yangtze River Delta Region have different industrial structures, consume energy in different ways and emit different pollutants. Hence, pollution control in these places should be focused on different issues. Studies till date were focused primarily on time-sequence or panel association work on emissions of specific pollutants in a region, and their applications were relatively limited. This paper uses dynamic data of the Logistic model to analyze the research approaches, validating both the rising tendency of the environmental Kuznets curve (EKC) and the differences in industrial pollutants from different regions in Yangtze River Delta through the use of the polynomial model. The proposed counter-measures are helpful in alleviating the pollutant emissions in the Yangtze River Delta Region and controlling the pollutant emissions in a structured manner across the region. Results show that there is a structural and spatial difference between industrial pollutant emissions and its economic growth in the Yangtze River Delta Region, and that the curve fitting model yields different inflection points and convergence times. The fitting curves for the three models demonstrate that the relation of industrial waste water, waste gas and " $3 \mathrm{~W}$ " (i.e. waste water, waste gas and solid waste) index with the regional GDP per capita takes on an inverse $\mathrm{N}$ shape, while the solid waste is linearly related to the regional GDP per capita.
\end{abstract}

Keywords: Industrial pollutant, spatial difference, structural difference, yangtze river delta region.

\section{THEORETICAL SURVEY}

The relation between pollutant emissions and the economic growth of a region was assessed by Martínez-Zarzoso I and Bengochea-Morancho [1] using the control samples and they concluded that the EKC-based classical hypothesis will be valid when the $\mathrm{CO}_{2}$ emissions have an elasticity balance between 0.4-2. With statistical data on population, incomes and technology in Canada and several other countries, Pierre-André Jouvet and Gilles Rotillon et al. [2] demonstrated the existence of the Environmental Kuznets Curve (EKC) for $\mathrm{CO}_{2}$ emissions in the context of technological development. Jack E. Riggs, Jeffrey C and Hobbs, Gerald R. Hobbs et al. [3] validated the inverse U-shaped relation between $\mathrm{CO}_{2}$ emissions and per capita income, and reported that the $\mathrm{CO}_{2}$ emissions in OECD members showed steady EKC characteristics. Martin Wagner [4] studied the relation between the industrial pollutant emissions and economic growth and proved that the different structures of industrial pollutants resulted in different critical points. Hence, different curve fitting models may yield different results while validating industrial pollutant emissions. Jill L, CavigliaHarris, Dustin Chambers, and James R. Kahn [5] recommended that the countries should devise policies to bring about more effective environmental control, reduce industrial pollutant emissions and achieve a green economy.

\section{MODEL SETTINGS AND CALCULATIONS}

2.1. The Environmental Kuznets Model For The Relation Between Industrial "3W" Emissions And Economic Growth

EKC is used in this paper to analyze the relation between industrial pollutant emissions and economic growth. Generally, it is verified by either a binomial or a polynomial. To further reduce the impact of hetero-scedasticity on the results, cubic polynomial dual-log verification is carried out to check the relation between environmental pollution and the driving force of industrial economy by setting up the basic model as follows:

$$
\ln y_{i}=\alpha_{i}+\beta_{1 i} \ln x+\beta_{2 i}(\ln x)^{2}+\beta_{3 i}(\ln x)^{3}+\varepsilon_{i}
$$

where the parameter $\mathrm{i}(1,2,3,4,5)$ is used to establish the EKC-based relation of waste gas, waste water, solid waste with comprehensive control over " $3 \mathrm{~W}$ " (i.e. waste gas, waste water, solid waste) pollution. EKC inflection points can be classified into the $\mathrm{N}$ type, inverse- $\mathrm{N}$ type, inverse- $\mathrm{U}$ type, $\mathrm{U}$ type, negative line and positive line. The critical conditions and inflection points for each type of fitting curves are described in Table 1.

\subsubsection{Emission and Economic Growth}

To study the overall trend of EKC in the context of progress in environmental protection, 1997 is chosen as the baseline. The path of inflection points for each sample in the Yangtze River Delta Region is selected. The investment in 
Table 1. Critical condition $\&$ inflexion of fitting curves for the correlations in industrial "3W".

\begin{tabular}{|c|c|c|}
\hline Curve Shape & Critical Condition & Inflexion \\
\hline \hline $\mathrm{N}$ & $\beta_{2 i}^{2}-3 \beta_{3 i} \beta_{1 i}>0 ; \beta_{3 i}>0$ & $3 \beta_{3 i}(\ln x)^{2}+2 \beta_{2 i}(\ln x)+\beta_{1 i}=0$ \\
\hline Inverted $\mathrm{N}$ & $\beta_{2 i}^{2}-3 \beta_{3 i} \beta_{1 i}>0 ; \beta_{3 i}<0$ & $3 \beta_{3 i}(\ln x)^{2}+2 \beta_{2 i}(\ln x)+\beta_{1 i}=0$ \\
\hline $\mathrm{U}$ & $\beta_{1 i}<0 ; \beta_{2 i}>0$ & $\ln x^{*}=-\frac{1}{2} \beta_{1 i} / \beta_{2 i}$ \\
\hline Inverted $\mathrm{ln} x^{*}=-\frac{1}{2} \beta_{1 i} / \beta_{2 i}$ \\
\hline Positive linear & $\beta_{1 i}>0 ; \beta_{2 i}<0$ & None \\
\hline Negative linear & $\beta_{1 i}>0 ; \beta_{2 i}=0$ & None \\
\hline
\end{tabular}

the environmental sector needed to achieve the predetermined degree of environmental protection is obtained by converting the magnitude of economy. The EKC mechanism for associating environment to economic growth is also acquired in this way. Detailed description is given below.

$d x / d t=\operatorname{ex}\left(1-{ }_{k}^{x}\right)$

where $x, k, r$ denote the model prediction variable, widest range of change and the parameter that needs to be estimated, respectively. Furthermore, $x$ can be transformed into a function of $k$, yielding

$Y=\ln \frac{k-x}{x}$ and $Y=\alpha-r t$

This can be simplified into

$$
\left(\frac{1}{x}+\frac{\frac{r}{K}}{r-\frac{r}{K} x}\right) d x=r d t \text {, yielding the general solution to }
$$

Equation (3) as:

$\ln |x|-\ln \left|r-\frac{r}{K} x\right|=r t+C$

Since $C$ is a constant and $C=\ln \left|\frac{x_{0}}{r-\frac{r}{K} x_{0}}\right|$, the equation that satisfies the original conditions is obtained.,

$$
\ln \left|\frac{x}{r-\frac{r}{K} x}\right|=\ln e^{n}+\ln \left|\frac{x_{0}}{r-\frac{r}{K} x_{0}}\right|=\ln \left|e^{n} \frac{x_{0}}{r-\frac{r}{K} x_{0}}\right|
$$

Simplifying it, then yields:

$$
\frac{x}{r-\frac{r}{K} x}=e^{n} \frac{x_{0}}{r-\frac{r}{K} x_{0}}
$$

The following inference can then be made:

$$
\begin{gathered}
x=e^{n} \frac{x_{0}}{r-\frac{r}{K} x_{0}} r-e^{n} \frac{x_{0}}{r-\frac{r}{K} x_{0}} \frac{r}{K} x, \\
x\left(\begin{array}{c}
r+e^{n} \frac{x_{0}}{r-\frac{r}{K} x_{0}} \frac{r}{K} \\
1+\frac{x_{0}}{K} x_{0}
\end{array}\right.
\end{gathered}
$$

Finally, the explanatory variable of the model is:

$$
\begin{gathered}
x=\frac{\frac{1}{e^{-n}\left(r-\frac{r}{K} x_{0}\right)}+\frac{1}{K} \frac{e^{-n}\left(1-\frac{r}{K} x_{0}\right)}{x_{0}}+\frac{1}{K}}{1+x_{0}}=\frac{1}{1\left(\frac{K}{x_{0}}-1\right)} \\
=\frac{1}{\left.1+e^{-n}\right)}
\end{gathered}
$$

\subsection{Parameter And Data Selection}

\subsubsection{Selection of Industrial Pollution and Economic Growth Metrics}

To further analyze pollutant structures, pollution products and " $3 \mathrm{~W}$ " pollutants are measured in 10,000 tons. To understand the impacts of " $3 \mathrm{~W}$ " pollutant landfilling and burning, the quantity of pollutants discharged is replaced by the quantity of pollutants generated. The " $3 \mathrm{~W}$ " pollutants are computed in a weighted manner. A detailed account of this is provided below.

$y=W_{1} M_{i 1}+W_{2} M_{i 2}+W_{3} M_{i 3}, i=1,2,3, \ldots 17$

This is used to describe the quantity of $3 \mathrm{E}$ pollutants discharged from 1997 to 2013, where $y_{i j}$ denotes the value of the $j^{\text {th }}$ pollutant in the $i^{\text {th }}$ year, $\bar{y}_{j}$ denotes the average of the corresponding discharge. Let $s_{j}$ denote the standard deviation of the discharge of $j$ predicted during the period from 1997 to 2013. Its weighted formula is given by: 


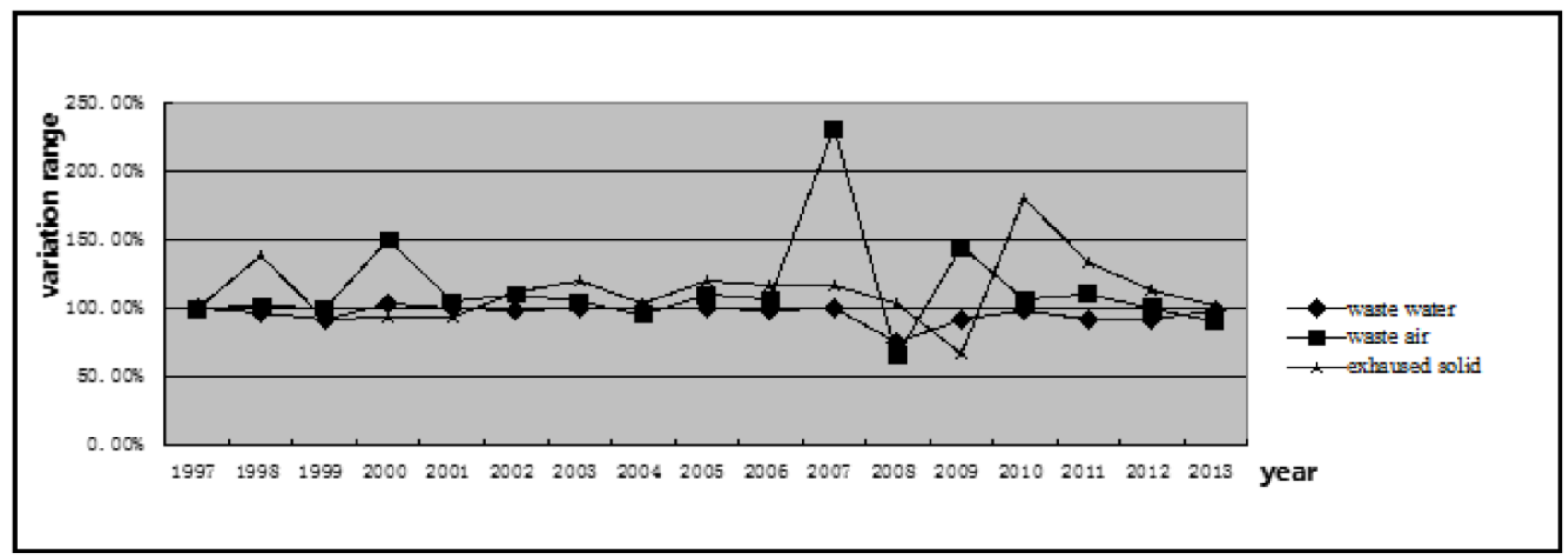

Fig. (1). Change trend of industrial "3W".

$M_{i j}=60+10 \times\left(y_{i j}-\bar{y}_{i}\right) / s_{j}, V_{j}=s_{j} /\left|\bar{y}_{j}\right|$

Therefore, the comprehensive " $3 \mathrm{~W}$ " index is given by:

$W_{j}=\frac{V_{j}}{\sum_{j=1}^{3} V_{j}}$

The per-capita GDP of Jiangsu, Zhejiang and Shanghai in the Yangtze River Delta Region serves as an indicator for growth of industrial economy. The year of 1996 is considered as the baseline. The deflator is derived by summarizing GDP indexes of these provinces from 1997 to 3013, with the data being collected from statistical annuals of these provinces. According to qualitative cognition and relevant theories that Gene M. Grossman et al. [6] (1995) devised on the mechanism for generation of industrial pollution, the relation between " $3 \mathrm{~W}$ " pollutants and industrial economic growth has been decomposed into many elements, such as the industrial structure, economic level, investment in environment protection, degree of urbanization and energy consumption.

(1) Industrial structure: as compared to light industry, the processing of aluminum for the construction industry in the Yangtze River Delta Region is a major contributor to energy consumption and pollutant emissions. Let $\mathrm{x} 0$ denote the selected indicator for industrial structure, which is measured by the proportion of the heavy industry (added value of the heavy industry/added value of the entire industry. Let $\mathrm{x} 1$ denote the Hoffman coefficient, i.e. added value of the light industry/added value of the heavy industry.

(2) Economic level: increase in the proportion of an industry will result in greater demand for energy and resources as well as more pollutant emissions. Increase in the gross economy results in greater pollutions. However, a stronger economy generates a potential for reducing pollutant emissions per product and increasing investment for improving the environment. Therefore, the concept of economic level is used in this paper. Let $\mathrm{x} 2$ denote GDP, $\mathrm{x} 3$ denote the added value of the industry. Then $x 4$ denotes the proportion of the added value of the industry, and is defined as the ratio of the added value of the industry to GDP (x3/x2).

(3) Environmental investment: the industrial investment in environmental protection is helpful in optimizing re- sources devoted to the industry and alleviating environmental pollution and pollutant emissions. Thus, the variable for the investment level of environmental protection is selected, which consists of investments on wastewater control, waste gas control and solid waste control as well as the overall investment needed to complete the environmental control task, these four dimensions being denoted by $\mathrm{x} 5 \sim \mathrm{x} 8$, respectively.

(4) Urbanization degree: The urbanization process is going on at a fast pace, resulting in greater energy demands, thereby generating more industrial pollutants and finally putting more pressure on the environment. The urbanization ratio is selected as the indicator, and is defined it as the ratio of the urban population to the resident population. Let it be denoted by $\times 9$.

(5) Energy consumption. It refers to the total energy consumed. Energy consumption is the most intuitive indicator for increase in emissions of industrial pollutants. The total consumption of primary energy leads to an increase in emissions of industrial pollutants. The total energy consumption and total coal consumption are chosen as sub-indicators and denoted as $\mathrm{x} 10$ and $\mathrm{x} 11$, respectively.

\subsubsection{Data}

This paper is focused on the relation between " $3 \mathrm{~W}$ " pollutants and economic growth in Yangtze River Delta Region comprising Jiangsu, Zhejiang and Shanghai. This relation is based on the industrial pollution data and on factors discussed above. The wastewater emission in the Yangtze River Delta Region decreases annually, but the solid waste and waste gas emissions increase dramatically as shown in Fig. (1). GDP in the Yangtze River Delta Region increases steadily during the years selected for statistical analysis.

\section{PROCESS FOR EMPIRICAL STUDY}

\subsection{EKC And Logistic Inflection Point Analysis On Eco- nomic Growth And Industrial Pollutant Emission}

Based on above analysis, EKC, coupled with the logistic model and multiple linear regression (MLR), is used to verify the relation between " $3 \mathrm{~W} "$ pollutants and economic growth in the Yangtze River Delta Region [7]. 
Table 2. Industrial "3W" and its synthetical estimation results for Yangze river delta.

\begin{tabular}{|c|c|c|c|c|c|c|c|c|c|c|c|}
\hline Pollutant & & $\mathbf{C}$ & $\ln x$ & $(\ln x)^{2}$ & $(\ln x)^{3}$ & $\mathbf{R}^{2}$ & $\mathbf{F}$ & DW & Curve & Inflexion & $\begin{array}{l}\text { Approach- } \\
\text { ing status }\end{array}$ \\
\hline \multirow{2}{*}{ waste water } & \multirow{2}{*}{$\mathrm{t}$} & 126.111 & -39.78 & 4.57 & -0.18 & \multirow{2}{*}{0.967} & \multirow{2}{*}{78.23} & \multirow{2}{*}{1.978} & \multirow{2}{*}{ Inverted $\mathrm{N}$} & 3218.57 & \multirow{2}{*}{$\downarrow$} \\
\hline & & $(1.78)$ & $(-1.67)$ & (1.77) & $(-1.85)$ & & & & & 10146.68 & \\
\hline \multirow{2}{*}{ exhaust gas } & \multirow{2}{*}{$\mathrm{t}$} & 509.71 & -170.13 & 19.15 & -0.71 & \multirow{2}{*}{0.968} & \multirow{2}{*}{130.01} & \multirow{2}{*}{1.957} & \multirow{2}{*}{ Inverted $\mathrm{N}$} & 3194.87 & \multirow{2}{*}{$\uparrow$} \\
\hline & & $(2.26)$ & $(-2.24)$ & $(2.28)$ & $(-2.28)$ & & & & & 19878.55 & \\
\hline \multirow{2}{*}{ waste solids } & \multirow{2}{*}{$\mathrm{t}$} & 1.44 & 0.94 & & & \multirow{2}{*}{0.959} & \multirow{2}{*}{356.11} & \multirow{2}{*}{1.981} & \multirow{2}{*}{$\begin{array}{l}\text { monotone } \\
\text { increasing }\end{array}$} & \multirow{2}{*}{ none } & \multirow{2}{*}{$\uparrow$} \\
\hline & & $(3.27)$ & (18.8) & & & & & & & & \\
\hline \multirow{2}{*}{$\begin{array}{l}\text { industrial } \\
\text { "3W" syn- } \\
\text { thetical }\end{array}$} & \multirow{2}{*}{$\mathrm{t}$} & 82.29 & -25.94 & 2.86 & -0.11 & \multirow{2}{*}{0.975} & \multirow{2}{*}{114.85} & \multirow{2}{*}{2.21} & \multirow{2}{*}{ Inverted $\mathrm{N}$} & 3487.03 & \multirow{2}{*}{$\downarrow$} \\
\hline & & $(1.96)$ & $(-1.83)$ & $(1.83)$ & $(-1.78)$ & & & & & 28639.21 & \\
\hline
\end{tabular}

Table 3. Model curve's NLS fitting per capita GDP.

\begin{tabular}{|c|c|c|c|c|}
\hline & Yangze River Delta & Shanghai & Zhejiang Province & Jiangsu Province \\
\hline \hline $\mathrm{R}^{2}$ & 0.97 & 0.998 & 0.994 & 0.97 \\
\hline $\mathrm{k}$ & 216136.71 & 226228.21 & 192628.71 & 168047.71 \\
\hline $\mathrm{a}$ & 4.39 & 4.25 & 4.21 & 0.18 \\
\hline $\mathrm{r}$ & 0.18 & 0.18 & $x=\frac{192628.71}{1+\mathrm{e}^{4.21-0.18 \mathrm{r}}}$ & $x=\frac{168047.71}{1+\mathrm{e}^{4.71-0.18 \mathrm{r}}}$ \\
\hline model & $x=\frac{216136.71}{1+\mathrm{e}^{4.39-0.18 \mathrm{r}}}$ & $x=\frac{226228.21}{1+\mathrm{e}^{4.25-0.18 \mathrm{r}}}$ & & \\
\hline
\end{tabular}

Table 4. Time estimation for the reachment of inflexion at "win-win" (industrial wastes \&GDP).

\begin{tabular}{|c|c|c|c|c|c|c|}
\hline \multirow{2}{*}{ Region } & \multicolumn{2}{|c|}{ Waste Water } & \multicolumn{2}{c|}{ Exhaust Gas } & \multicolumn{2}{c|}{ Waste Solids } \\
\cline { 2 - 7 } & Number of Years & Year & Number of Years & Year & Number of Years & 2014 \\
\hline \hline Yangze river delta & reached & 2006 & 0.67 & 2014 & 0.95 & 1.97 \\
\hline Shanghai & reached & 2007 & reached & 2013 & 3.17 & 2015 \\
\hline Jiangsu prov. & reached & 2005 & reached & 2012 & 4.12 & 2017 \\
\hline Zhejiang prov. & reached & 2006 & 4.85 & 2017 & \\
\hline
\end{tabular}

Results of analysis performed on the Yangtze River Delta Region, using above selected environmental pollution indicators, are shown in Table $\mathbf{2}$. The constant term and the parameter of $t$ that needs to be estimated was derived from regression of various curve models, goodness-of-fit of their corresponding equations being $0.967,0.968$ and 0.959 , respectively. In terms of sequence correlation, since the DW values of each curve model are 1.978, 1.957 and 1.981, respectively, autocorrelation of the corresponding sequences was completely eliminated, thereby removing the need to add the AR variable [8].

Based on above analysis, the model curves of per-capital GDP in the Yangtze River Delta Region were fitted through the use of the Logistic model. Results in Table 3 demonstrated that the industrial waste gas and solid wastes in the Yangtze River Delta Region bear a significant and positive relation to economic growth of the region, without EKC inflection points. But the industrial " $3 \mathrm{~W}$ " pollutants and $W_{j}$ bear an inverse "N" relation to the economic growth achieved in the Yangtze River Delta Region for the corresponding years $[9,10]$.

In above relations, the per-capital GDP that corresponded to the inflection point from increased economic growth and alleviated pollution is reported to be 10148.68 yuan, 19878.55 yuan and 28639.21 yuan, as showed respectively in Table 4. Next, the per-capital GDP data issued to obtain the time path that the Yangtze River Delta Region follows to contact the EKC. Results demonstrate that in terms of industrial waste gas pollution, Shanghai and Jiangsu approach the inflection point at the peak; but in terms of solid waste pollution, there is still room for pollution control. 


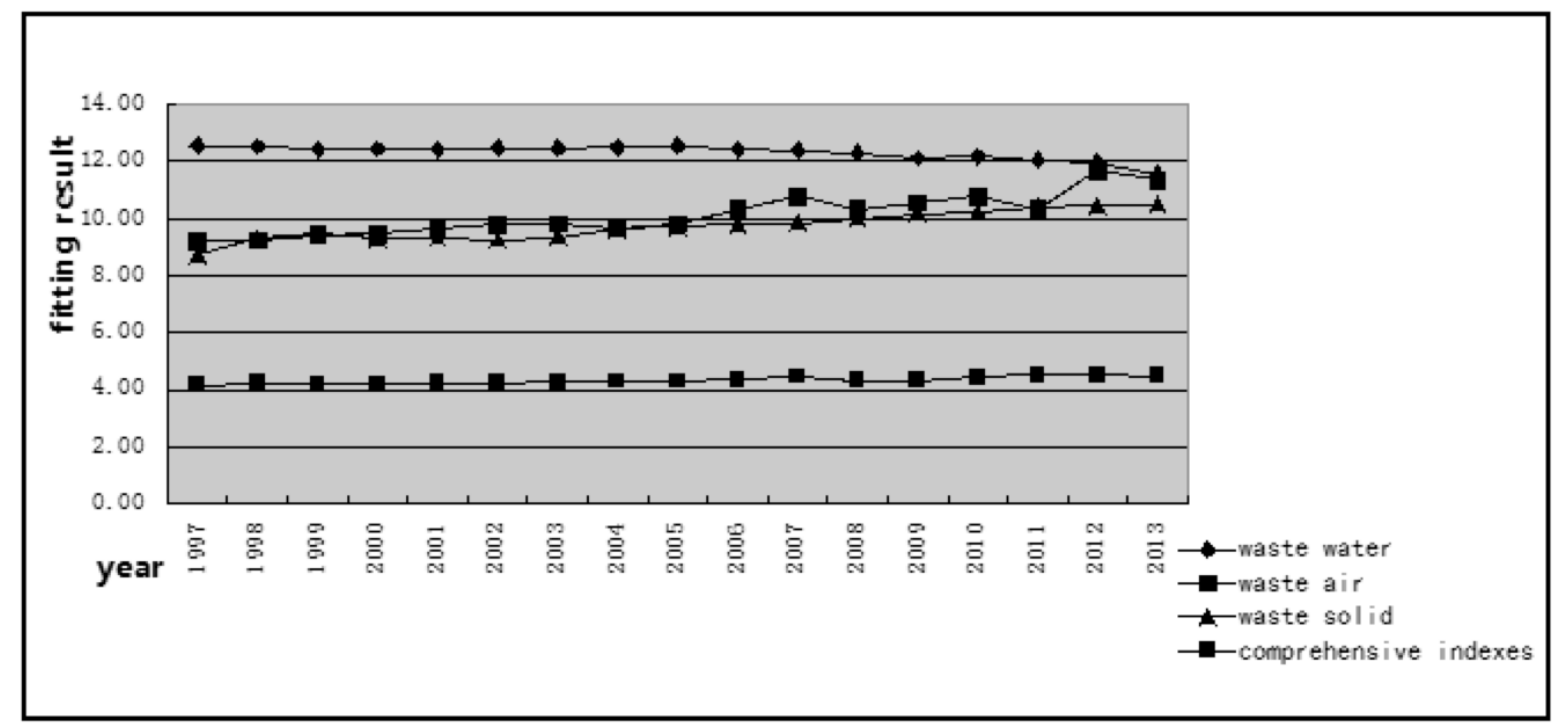

Fig. (2). Fitting results in logarithm curve for industrial "3W" in yangtze river delta.

\subsection{Model Verification On Yangtze River Delta Region's Influencing Factors of The Industrial "3W" Emission}

Results from fitting the emissions of industrial waste water in the Yangtze River Delta Region fluctuated are showed in the following Fig. (2).

Firstly, the emission of industrial pollutants was inversely related to the per-capita GDP before 1996, and positively related to it from 1996 onwards till 2007. For now, the relation between the structure of the source of pollution in the Yangtze River Delta Region and its economic growth can be characterized by "high economic growth and low level of pollution". This benefits from the collaborative pollution control measures across the region, where the distribution of enterprises is adjusted, and some of the enterprises that threaten serious pollutions are transferred elsewhere. However, there are more resource-intensive enterprises that entail high energy consumption per unit of production, resulting in an increase in the emission of industrial waste water again. It can be said that exercising pollution control is an important means for enterprises of the Yangtze River Delta Region to alleviate emissions of industrial " $3 \mathrm{~W}$ " pollutants [11-13].

Secondly, in terms of the fitting curve of industrial waste gas emissions, the industrial waste gas emissions decreased before 1996, rose rapidly after 1996 and then increased slowly. The inflection point in the industrial waste gas curve in the Yangtze River Delta Region corresponded to the percapita GDP of 19887.57 yuan, compared to the per-capita GDP of 18807.16 yuan for the region. It is predicted that the above inflection point would be reached in 2015. Both Shanghai and Zhenjiang, are inclined to show a characteristic "high economic growth and low pollution level", taking into account the inflection points at the bottom of their fitting curves on emissions, the curve tendency to increase since the inflection points were formed gradually in 2001 and their efforts to shut down or transfer serious-polluting enterprises. Note that there are still some industries heavily dependent on resources, thereby slowing down the pace of the region to approach the "high economic growth and low pollution level" inflection point. In regions where energy-intensive enterprises are concentrated, it is advised to devise environmental protection regulations and prompt the industries to exercise pollution control.

Thirdly, the solid waste emissions in the Yangtze River Delta Region were positively related to the per-capita GDP. The main reason for this is that while adjusting the industrial structures, a large number of energy-intensive raw materials were used across the region, and the byproducts contributed to the solid waste pollution. Meanwhile, only small investments were made on pollution control. In this context, high economic growth was achieved at the cost of serious pollution. In case of the Yangtze River Delta Region, sufficient attention should be paid to pollution control before, during and after the production processes.

Next, the fitting curve of the relation between the " $3 \mathrm{~W} "$ comprehensive index and the economic growth across the Yangtze River Delta Region first descended and then ascended. After 1996, the increase was steadily reduced. The per-capita GDP inflection point of the " $3 \mathrm{~W}$ " comprehensive index was kept at 28638.27 yuan, compared to 18807.13 yuan for the Yangtze River Delta Region. It is predicted that the inflection point would be reached in 2017. Due to different conditions prevailing in cities, Shanghai and Jiangsu would reach this point prior to Zhejiang.

\subsection{Double-Log Regression Analysis of the Relation Be- tween Industrial "3W" Emissions and Economic Growth}

Based on above analysis, various models are used in this paper to represent different properties of the relation between the source of the industrial pollution and the per-capita GDP across the region. Due to multi-dimensional samples, autoregression on the above two factors is performed quantitatively using the double logarithmic method in order to obtain the relation between industrial " $3 \mathrm{~W}$ " emissions and economic growth.

$$
\begin{aligned}
& \ln y_{i}=\beta+\beta_{0} \ln x_{0}+\beta_{1} \ln x_{1} \\
& +\beta_{2} \ln x_{2}+\ldots \beta_{n} \ln x_{n}+\mu
\end{aligned}
$$


where $\beta$ denotes the coefficient of each explanatory variable, and $\mu$ denotes the random disturbance term. Industrial structure, degree of urbanization, economic activity, investments in environmental protection, and energy consumption are defined as the explanatory variables to construct their relation with the dependent variable $y_{i}$. Next, Eview software is run to analyze the relation between the industrial " $3 \mathrm{~W}$ "" emissions and the economic growth in the Yangtze River Delta Region. Double logarithmic quantitative regression and principal component fixed-effect variable intercept panel regression are carried out to avoid multiple contributions. In general least squares verification, let $\operatorname{lny}_{w . w .}, \operatorname{lny}_{\mathrm{w} . \mathrm{g} \text {, }}$ $\operatorname{lny}_{\text {w.s. }}$ and $\operatorname{lny}_{\text {T.w }}$ denote the waste water index, waste gas index, solid waste index and the " $3 \mathrm{~W}$ " comprehensive index, respectively. The model is given as follows:

$$
\begin{aligned}
& \text { i. } \operatorname{lny}_{\mathrm{w} . \mathrm{w} .}=11.87-0.65 \mathrm{~F}_{3}-0.44 \mathrm{~F}_{4}+0.47 \mathrm{AR}(1) \\
& \text { (20.63) (-2.51) (-2.71) (7.98) } \\
& \mathrm{R}^{2}=0.97 \mathrm{~F}=309.81 \mathrm{DW}=1.67 \\
& \text { ii.lny } y_{\text {w. } .=}=0.14+1.08 \mathrm{~F}_{1}-0.44 \mathrm{~F}_{2}-0.47 \mathrm{~F}_{4}+0.47 \mathrm{AR}(1) \\
& (-0.18)(11.87)(-2.88)(6.71)(3.84) \\
& \mathrm{R}^{2}=0.94 \mathrm{~F}=100.25 \mathrm{DW}=2.14 \\
& \text { iii.lny } \text { w.s. }=2.47+0.82 \mathrm{~F}_{1}-0.54 \mathrm{~F}_{2}-0.58 \mathrm{~F}_{3}+0.50 \mathrm{AR}(1) \\
& \text { (5.87) (14.67)(-5.35)(-9.23) (4.14) } \\
& \mathrm{R}^{2}=0.97 \mathrm{~F}=379.81 \mathrm{DW}=1.87
\end{aligned}
$$

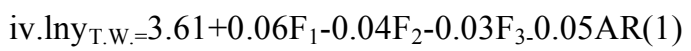

$$
\begin{aligned}
& \text { (40.46) (4.67) (-2.25) (-3.71) (5.14) } \\
& \mathrm{R}^{2}=0.90 \mathrm{~F}=63.25 \mathrm{DW}=2.16
\end{aligned}
$$

\subsection{Results}

Based on above analysis, the goodness-of-fit of each model is $0.917,0.978,0.955$ and 0.937 , all being close to 1 . The DW statistics for residual errors reports 1.957, 1.938, 1.986 and 1.984 , all being close to 2 . This proves there is no possibility for auto-correlation amongst the parameters. The constant terms and the changes of each parameter in the four models pass the t-value test at a high level, demonstrating that the selected multi-variable double logarithmic quantitative regression model produces good fitting results. Thereafter, the principal component analysis is carried out to interpret the relation between each of the factors and the industrial " $3 \mathrm{~W}$ " pollutant emissions. Fitting of these data yields the elastic coefficients for the industrial " $3 \mathrm{~W}$ " pollutants and the comprehensive " $3 \mathrm{~W}$ " pollutants. Taking into account multi-variable double logarithmic quantitative regression, it proves that different factors have different relations with the industrial " $3 \mathrm{~W}$ " pollutants in the Yangtze River Delta Region.

Firstly, the elements of the industrial structure in the Yangtze River Delta Region bear the most significant relation to industrial waste gas emissions. Increase in industrialization and Hoffman proportion by $1 \%$ results in an increase in the waste gas emissions by $1 \%$. The increase in the waste gas emissions will be even greater, in the context of growing proportions of heavy industries across Yangtze River Delta
Region, especially when these heavy industries involve aluminum materials, processing units, and petrochemicals.

Secondly, both the economic level and the proportion of the industry across the region to the industry in the country are positively related to the industrial " $3 \mathrm{~W}$ " and comprehensive indexes, but are negatively related to waste water. GDP increase, industrial increment, and the proportion of the industrial increment to the national GDP by $1 \%$, result in a reduction of waste water emissions by $0.03 \%, 0.05 \%$ and $0.27 \%$, an increase in waste gas emissions by $0.16 \%, 0.18 \%$ and $0.38 \%$, an increase in solid waste emissions by $0.07 \%$, $0.09 \%$ and $0.09 \%$, as well as an increase in the industrial " $3 \mathrm{~W}$ " emissions by $0.01 \%$. From Table 1 , it is observed that a greater economic output and industrial growth result in a higher level of " $3 \mathrm{~W}$ " pollutions from the industry; but the technology for reducing waste water emissions offsets " $3 \mathrm{~W}$ " comprehensive emissions, further proving that there is room for cities in the Yangtze River delta region to exercise greater control over industrial " $3 \mathrm{~W}$ " pollutions.

Furthermore, elements of the urbanization process and solid waste emissions bear a positive and significant relation to an economic growth across the region. Fluctuations in waste water and solid waste emissions are readily caused during the urbanization process. Increase in urbanization degree by $1 \%$ results in an increase in the industrial waste water and solid waste emissions by $0.16 \%$ and $0.15 \%$, respectively. This indirectly proves that the urbanization process prompts enterprises to boost production blindly, resulting in higher level of pollution. But " $3 \mathrm{~W}$ " pollution control has a slight and positive relation to the level of industrial pollution. This is mainly due to the fact that the cost in pollution control is investment-type expenditure. But the industry usually follows a mode that postpones environmental protection until the pollution has already occurred, highlighting the need for a further control from the government, while investing more in pollution abatement.

Finally, energy consumption, especially coal consumption, is significantly related to industrial waste gas and solid waste emissions. Increase in energy consumption by $1 \%$ implies that the industrial waste gas and solid waste emissions increase by $0.28 \%$ and $0.32 \%$, respectively. Increase in coal consumption by $1 \%$ implies that the industrial waste gas and solid waste emissions increase by $0.37 \%$ and $0.18 \%$, respectively. This demonstrates the significant relation of energy and coal consumption to the industrial waste gas and solid waste emissions. This is due to the control over industrial waste water emissions throughout the Yangtze River Delta Region.

\section{CONCLUSION AND RECOMMENDATION}

Environmental pollutions associated with industrial development bear many relations to economic growth. The fitting curves of different models yield different verification results on various industrial pollutants across provinces and cities in the Yangtze River Delta Region. Jiangsu and Shanghai approach the "high economic growth and low energy consumption" inclusion points faster than Zhejiang. Structural study on the relation of industrial pollutants and their emissions with economic growth in the Yangtze River Delta Region has been carried out. Feasible ideas on water 
pollution control that can be implemented by the industry are proposed. In terms of industrial waste water emissions, based on validation of different injection points for emissions across the region, this paper throws light on the introduction of structural pollution control into industries in the Yangtze River Delta Region as well as on the adjustment and selection of these industries. Due to different validation results between Shanghai, Jiangsu and Zhejiang, in terms of protection of water environment, more efforts need to be taken to abate solid waste and industrial waste gas pollutions. Finally, taking into account its comparison with Shanghai and Jiangsu in terms of inflection point for industrial pollution control, Zhejiang needs to extend the mode of industrial waste water control into waste gas and solid waste pollution abatement, enabling industrial " $3 \mathrm{~W}$ " pollution to be controlled by collaborative efforts across the Yangtze River Delta Region.

\section{CONFLICT OF INTEREST}

The author confirms that this article content has no conflict of interest.

\section{ACKNOWLEDGEMENTS}

This work is supported by the general project of the Education Office of Zhejiang province in 2014, China (No. Y201432018), the research subject of Zhejiang society scientific circles federation in 2014, China (2014B142).

\section{REFERENCES}

[1] M.Z. Inmaculada, B.M. Aurelia, and M.L. Rafael, "The impact of population on $\mathrm{CO}_{2}$ emissions: evidence from European countries," Environmental and Resource Economics, vol. 38, no. 4, pp. 497$512,2007$.
[2] P.A. Jouvet, and G. Rotillon, "Capital allocation and international equilibrium with pollution permits," Modern Economy, vol. 3, no. 2, pp. 187-199, 2012.

[3] W.G. Park, and D.A. Brat, "A global Kuznets curve?" KYKLOSBERNE-, vol. 48, pp. 105-105,1995.

[4] M. Wagner, "The carbon Kuznets curve: A cloudy picture emitted by bad econometrics?," Resource and Energy Economics, vol. 30 , no. 3, pp. 388-408, 2008.

[5] J.L. Caviglia-Harris, D. Chambers, and J.R. Kahn, "Taking the "U"out of Kuznets: a comprehensive analysis of the EKC and environmental degradation," Ecological Economics, vol. 68, no. 4, pp. 1149-1159, 2009.

[6] G.M. Grossman, and A.B. Krueger, "Economic growth and the environment," Quarterly Journal of Economics, vol. 110, no. 2, pp. 353-377, 1995.

[7] S. Kalimunjaye, M. Olobo, and S. Kyakulumbye, "Carbon trade financing strategies and opportunities for competitiveness of private sector SMEs in Uganda," Technology and Investment, vol. 3 , 4, pp. 244-251, 2012.

[8] J.G. Tamba, F.D. Koffi, L. Monkam, S.K. Ngoh, and S.N. Biobiongono, "Carbon dioxide emissions from thermal power plants in cameroon: a case study in dibamba power development company," Low Carbon Economy vol. 4, pp. 35-40, 2013.

[9] A. Sampaolesi, "Optimal environmental policy under endogenous terms of trade and economic growth," Theoretical Economics Letters, vol. 4, no. 7, pp. 608-611, 2014.

[10] R.W. Allen, E. Gombojav, B. Barkhasragchaa, T. Byambaa, O. Lkhasuren, O. Amram, and C.R. Janes, "An assessment of air pollution and its attributable mortality in Ulaanbaatar, Mongolia," Air Quality, Atmosphere \& Health, vol. 6, no. 1, pp. 137-150, 2013.

[11] D. Infante, J. Smirnova, "Some Notes on Modelling the Relationship between the Environment and Institutional Context," Modern Economy, vol. 2, no. 1, pp. 18-24, 2011.

[12] D. Amarsaikhan, V. Battsengel, and B. Nergui, M. Ganzorig, and G. Bolor, "A Study on Air Pollution in Ulaanbaatar City, Mongolia," Journal of Geoscience and Environment Protection, vol. 2, no. 2, pp. 123-128, 2014.

[13] A. Thompson, "Accounting for Population in an EKC for Water Pollution," Journal of Environmental Protection, vol. 4, no.7, pp. 147-150, 2013.

(C) Shen Fei; Licensee Bentham Open.

This is an open access article licensed under the terms of the (https://creativecommons.org/licenses/by/4.0/legalcode), which permits unrestricted, noncommercial use, distribution and reproduction in any medium, provided the work is properly cited. 